Original Research Article

\title{
Bupivacaine $0.5 \%$ vs. levobupivacaine $0.5 \%$ for epidural anaesthesia for caesarean section: a comparative study
}

\author{
Heena D. Pahuja, Megha P. Tajne*, Anjali R. Bhure, Savita M. Chauhan
}

\begin{abstract}
Department of Anaesthesia, NKP Salve Institute of Medical Sciences, Nagpur, Maharashtra, India
\end{abstract}

Received: 18 November 2017 Accepted: 28 December 2017

*Correspondence to:

Dr. Megha P. Tajne,

Email: uikeymegha@ rediffmail.com

Copyright: (C) the author(s), publisher and licensee Medip Academy. This is an openaccess article distributed under the terms of the Creative Commons Attribution NonCommercial License, which permits unrestricted noncommercial use, distribution, and reproduction in any medium, provided the original work is properly cited.

\begin{abstract}
Background: Levobupivacaine has been purported to be as efficacious as Bupivacaine for epidural anaesthesia in recent literature.

Methods: With the intent to study the same in caesarean section cases in our set up, we observed various intra- and post-operative variables in two groups (Levobupivacaine and Bupivacaine) of 60 healthy parturients. Sixty parturients for elective caesarean section were allocated randomly to receive epidural block with $10-20 \mathrm{ml}$ of either $0.5 \%$ Levobupivacaine with Fentanyl $25 \mu \mathrm{g}$ or $0.5 \%$

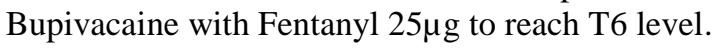

Results: Mean total volume in Bupivacaine group was $15.23 \mathrm{ml}$ and in Levobupivacaine group was $12.76 \mathrm{ml}$. The difference was statistically significant. There was significant difference between the groups in the sensory block. The onset of analgesia was earlier in Levobupivacaine group. Mean time was 6.20 minutes in Bupivacaine group and 4.36 minutes in Levobupivacaine group. The duration of motor block was significantly short in Levobupivacaine group. Mean Time for recovery from motor block in Bupivacaine group was 2.5 hours and in Levobupivacaine group 1.5 hours. Mean time to achieve T6 height was earlier in Levobupivacaine group i.e. 16.46 minutes in Bupivacaine group and 13.26 minutes in Levobupivacaine group. Duration of postoperative analgesia was similar. There was no significant difference in neonatal outcome.

Conclusions: Levobupivacaine was found to fare better than Bupivacaine in the studied intra and post-operative parameters and is hence recommended over racemic Bupivacaine for epidural block in patients undergoing elective cesarean section.
\end{abstract}

Keywords: Anaesthesia, Bupivacaine, Caesarean section, Epidural, Levobupivacaine, Obstetric

\section{INTRODUCTION}

Epidural anesthesia for caesarean section is increasing because of labor epidural analgesia which helps the conversion to anaesthesia when needed. Currently most common drug for obstetric epidural anaesthesia is Bupivacaine. Bupivacaine is a racemic mixture consisting of equal amounts of the optic isomers levobupivacaine and dextrobupivacaine, also known as $\mathrm{S}(-)$ and $\mathrm{R}(+)$ enantiomers. ${ }^{1}$ It is well known that racemic Bupivacaine has a narrow therapeutic index and carries higher risk for cardiotoxicity. Based on demonstrations that racemic Bupivacaine cardiotoxicity is enantioselective that is more pronounced with $\mathrm{R}(+)$ enantiomer, S (-) enantiomer was developed for clinical use. ${ }^{2}$ Levobupivacaine is purported to offer certain advantages over Bupivacaine in obstetric anesthesia; like less cardiac and CNS toxicity, less hypotension (an advantage in obstetric anaesthesia as it helps maintain utero-placental circulation) and provides more differential block when given epidurally i.e. early sensory block and less intense motor block with early motor recovery - helps in early ambulation. ${ }^{3,4}$ The reduced toxic profile of Levobupivacaine is beneficial for achieving higher plasma concentrations and dose without signs of cardiovascular or systemic toxicity. Furthermore, the success rate of cardiopulmonary resuscitation after toxic doses of levobupicaine is higher compared to 
Bupivacaine intoxication. ${ }^{5}$ There is relative paucity off late of studies describing the use of Levobupivacaine $0.5 \%$ and its advantages thereof, if any, over Bupivacaine $0.5 \%$ in obstetric anesthesia. This study was aimed at comparing characteristics and outcomes with epidural block with Bupivacaine or Levobupivacaine for elective caesarean section in healthy parturients.

\section{METHODS}

The aim of this study was to assess the clinical efficacy of $0.5 \%$ levobupivacainie with fentanyl $25 \mu \mathrm{g}$ when given Epidurally. A double-blind comparison was made with $0.5 \%$ Bupivacaine with fentanyl $25 \mu \mathrm{g}$. Maternal sensory and motor block, haemodynamic changes, neonatal outcome and side effects were compared.

Sixty parturients for elective caesarean section were allocated randomly to receive epidural block with either $0.5 \%$ Bupivacaine with fentanyl or $0.5 \%$ levobupivacaine with fentanyl. Study type were randomized, controlled, double blind. Sample size are 30 patients per group.

Study was conducted at Department of Anesthesiology, NKP Salve Institute of Medical Sciences, Nagpur, Maharashtra, India. The period of study was conducted from April 2015 to March 2016.

\section{Inclusion criteria}

- $\quad$ ASA I and II patients

- Healthy parturients posted for elective caesarean section

\section{Exclusion criteria}

- Allergy to local anesthetics

- Patients with medical diseases

- Local sepsis

- General contraindication against epidural block

- Group-B: $15-20 \mathrm{ml}$ of $0.5 \%$ Bupivacaine $+25 \mu \mathrm{g}$ fentanyl in epidural space

- Group-L: 15 - $20 \mathrm{ml}$ of $0.5 \%$ Levobupivacaine +25 $\mu \mathrm{g}$ fentanyl in epidural space

After obtaining informed written consent, 60 pregnant women (ASA 1 or 2), undergoing elective caesarian section were included in study. All were full term $>36$ weeks, with single fetus, age above 18 Years, height $>150 \mathrm{~cm}$, body weight $50-80 \mathrm{Kg}$ and estimated fetal weight $>2500$ grams. Exclusions included women with diabetes mellitus and known allergy to amide local anesthetics and patients with contraindication for epidural block. Patients were randomly allocated to the mentioned groups immediately before the anesthetic procedure. Neither the investigator in-charge of data collection nor the patients knew the group they belonged to. Anesthetic procedure was standardized and performed by an investigator not involved in data collection.
All women were pre-medicated with injection ranitidine and given i.v. Ringer lactate solution $500 \mathrm{ml}$ just before the procedure.

After taking written informed consent of the patient, patient was randomly allocated to either group B or group L. Patient's basic vital parameters were recorded, and Cardiac Monitoring was setup. IV line was secured. Patient's position for conduct of epidural block was lateral with spine flexion. Under all aseptic precaution L2-L3 or L4-L5 space was identified and local Anaesthesia given with $2 \%$ Lignocaine. Epidural needle pierced in the space and epidural space identified with loss of resistance technique. Epidural catheter was threaded in epidural space. catheter fixed at the back and $3 \mathrm{ml}$. of $2 \%$ Lignocaine with adrenaline was injected through catheter in epidural space as test dose to confirm that it was in epidural space and hadn't punctured dura or any vessel (if puncture of dura - patient gets paresthesia and weakness; if vessel is punctured, there is sudden rise of pulse rate and blood pressure). Once it was sure that catheter was in the epidural space, Levobupivacaine or Bupivacaine 15-20ml was injected slowly. Initial $15 \mathrm{ml}$ was injected and observed by a person whose was blinded to the drug injected and additional $2 \mathrm{ml}$ increments given, if required, to achieve T6 level. Uterus was displaced with wedge in all the patients. Moment zero was defined as end of epidural injection. Sensory block level was determined by the lack of painful sensitivity at $25 \mathrm{G}$ needle prick on the mid axillary line at 5, 10, 15 and 20 minutes. Surgery was not started until analgesia to pinprick was achieved bilaterally to T6. If block did not reach T6 within 15 minutes, an additional $5 \mathrm{ml}$ of study drug was given. If needed another $5 \mathrm{ml}$ given 10 minutes after main dose. If block did not reach T6 after 30 minutes, patient was withdrawn from further efficacy assessments and the epidural converted to spinal or general anesthesia. Motor block was assessed bilaterally at the same time interval using Modified Bromage scale..$^{6,7}(0=$ no paralysis-full flexion of hip, knee, ankle. 1= Unable to flex hip, able to flex knee and ankle, $2=$ unable to flex hip and knee. 3= unable to flex hip, knee, ankle joint).

Following parameters were observed in both the groups:

- Onset of Analgesia

- $\quad$ Onset of motor block (Bromage scale- 1)

- Height of block (Sensory)

- BP, Pulse rate, Oxygen saturation, ECG

- Supplementation of block, if required

- Baby apgar score at 1 and 5 min.

- Recovery from motor block (Bromage scale 2)

- Post-operative analgesia -pain score (Visual analogue scale 0-10)

- Duration of analgesia- time when patient needs 1 st analgesic in post-operative period

Statistical analysis was done using statistical software STATA (Version 11). Student's unpaired t-test was applied for comparisons. 


\section{RESULTS}

Thirty-two patients received levobupivacaine with fentanyl and thirty-one patients received bupivacaine with fentanyl. One patient from bupivacaine group and two patients from Levobupivacaine group developed very limited block at the end of 30 minutes and were withdrawn from further study as cases of technical failure and later had to be converted to spinal anaesthesia. There were no accidental dural punctures or blood in catheter. The groups were similar in age, weight, height, and number of ASA 1 and 2 patients.

Total volume of drug required to achieve height T6. In Bupivacaine group total volume of drug required was $15.23 \mathrm{ml}$ and in Levobupivacaine group total volume of drug was $12.76 \mathrm{ml}$. Levobupivacaine group required less volume of drug. P-value is $<0.05$ which is statistically significant (Table 1).

Table 1: Comparison of total volume in bupivacaine and levobupivacaine group.

\begin{tabular}{|lllll|}
\hline Group & N & Mean $(\mathbf{m l})$ & SD & P-value \\
\cline { 1 - 4 } Bupivacaine & 30 & 15.23 & 1.86 & 0.000 \\
\cline { 1 - 4 } Levobupivacaine & 30 & 12.76 & 2.78 & $\mathrm{p}<0.05$ \\
\hline
\end{tabular}

Comparison of onset of analgesia in bupivacaine and levobupivacaine group. In bupivacaine group onset of analgesia mean time was 6.20 minutes. And in Levobupivacaine group mean time was 4.36 minutes value is $\mathrm{p}<0.05$, showing statistically significant early onset of analgesia in levobupivacaine group (Table 2).

Table 2: Comparison of onset of analgesia in Bupivacaine and Levobupivacaine group.

\begin{tabular}{|lllll|}
\hline Group & N & $\begin{array}{l}\text { Mean time } \\
\text { (minute) }\end{array}$ & SD & P-value \\
\cline { 1 - 4 } Bupivacaine & 30 & 6.20 & 1.24 & 0.000 \\
\cline { 1 - 4 } Levobupivacaine & 30 & 4.36 & 1.18 & $(\mathrm{p}<0.05)$ \\
\hline
\end{tabular}

Table 3: Comparison of onset of motor block in bupivacaine and levobupivacaine group.

\begin{tabular}{|lllll|}
\hline Group & $\mathbf{N}$ & $\begin{array}{l}\text { Mean time } \\
\text { (minute) }\end{array}$ & SD & P-value \\
\cline { 1 - 4 } Bupivacaine & 30 & 11.60 & 4.59 & 0.254 \\
\cline { 1 - 4 } Levobupivacaine & 30 & 12.66 & 2.13 & $(\mathrm{p}>0.05)$ \\
\hline
\end{tabular}

Comparison of onset of motor block in Bupivacaine and Levobupivacaine group. In Bupivacaine group mean time for onset of motor block (Bromage scale 1) was 11.60 minutes and in Levobupivacaine group it was 12.66 minutes. In Bupivacaine group onset of motor block was early; but $\mathrm{p}>0.05$, i.e. statistically insignificant difference (Table 3).
Comparison of time to start surgery in bupivacaine and levobupivacaine group. In bupivacaine group mean time to achieve height T6 for analgesia to start surgery was 16.46 minute and in levobupivacaine group mean time to achieve analgesia at T6 to start surgery was 13.26 minutes. In levobupivacaine group analgesia at T6 was achieved early which is statistically significant with $\mathrm{p}<0.05$ (Table 4).

Table 4: Comparison of time to start surgery in bupivacaine and levobupivacaine group.

\begin{tabular}{|lllll|}
\hline Group & N & $\begin{array}{l}\text { Mean time } \\
\text { (minute) }\end{array}$ & SD & p-value \\
\cline { 1 - 3 } Bupivacaine & 30 & 16.46 & 5.18 & 0.004 \\
\cline { 1 - 4 } Levobupivacaine & 30 & 13.26 & 2.79 & $(\mathrm{p}<0.05)$ \\
\hline
\end{tabular}

Comparison of duration of postoperative analgesia in bupivacaine and levobupivacaine group. In bupivacaine group mean duration of postoperative analgesia was 5.59 hours and in levobupivacaine group mean duration of postoperative analgesia was 5.58 hours. Postoperative analgesia is similar in both groups and p-value is $>0.05$ (statistically not significant) (Table 5).

Table 5: Comparison of duration of post-operative analgesia in bupivacaine and levobupivacaine group.

\begin{tabular}{|c|c|c|c|c|}
\hline Group & $\mathbf{N}$ & $\begin{array}{l}\text { Mean time } \\
\text { (minute) }\end{array}$ & SD & p-value \\
\hline Bupivacaine & 30 & 5.59 & 1.05 & \multirow{2}{*}{$\begin{array}{l}0.954 \\
(p>0.05)\end{array}$} \\
\hline Levobupivacaine & 30 & 5.58 & 0.68 & \\
\hline
\end{tabular}

Recovery from motor block was significantly earlier in levobupivacaine group. Mean time was 1.5 hours for recovery from motor block (Bromage scale 2) in levobupivacaine group and 2.5 hours in bupivacaine group.

All the patients in both the groups were hemodynamically stable. Apgar score was more than 7 in all the babies. No significant complications were there in patients from both the groups in intraoperative and postoperative period.

\section{DISCUSSION}

Comparative studies of the effects of epidural bupivacaine and levobupivacaine are getting commoner by the day, with the advantages offered by levobupivacaine over racemic bupivacaine w.r.t. therapeutic index and cardiotoxicity. ${ }^{8}$ Effects of both the drugs over intra and post-operative parameters in various procedures are being studied off late and comparisons drawn. Fesih et al studied effects of epidural $0.5 \%$ bupivacaine and $0.5 \%$ levobupivacaine in hip and lower extremity surgeries and reported Levobupivacaine to be a good alternative in terms of hemodynamic parameters, quality of anesthesia and analgesia, patient and surgeon satisfaction and complications. ${ }^{9}$ Rita $\mathrm{C}$ et al compared intra and postoperative analgesia with local levobupivacaine and 
bupivacaine in elderly males undergoing inguinal hernioplasty and concluded that clinical efficacy of levobupivacaine and racemic bupivacaine were essentially similar. ${ }^{10}$ Nauman et al evaluated the quality and efficacy of peribulbar blockade for superficial extraconal anesthesia with levobupivacaine $0.5 \%$ and bupivacaine $0.5 \%$, both combined with lidocaine $2 \%$, for patients undergoing phacoemulsification and reported similar block quality and efficacy. ${ }^{11}$

In the present study, we aimed at comparing characteristics and outcomes with epidural block with bupivacaine or levobupivacaine in elective caesarean section cases. To study this is particularly relevant, given higher volume of drug usage in epidural anesthesia. Sixty healthy parturients posted for elective caesarean section were allocated randomly to receive epidural block with either $0.5 \%$ Bupivacaine with fentanyl or $0.5 \%$ levobupivacaine with fentanyl and various intra-operative and post-operative variables were observed in the two groups.

In present study, levobupivacaine group required significantly less total volume of drug to achieve height T6. The volume of drug used in previous studies was $20 \mathrm{ml}$ $30 \mathrm{ml}^{7,12}$ Volume required in both the groups was presumably less because $25 \mathrm{mcg}$ of fentanyl was added.

Significantly early onset of analgesia was observed in levobupivacaine group (4.36 minutes) in comparison to bupivacaine $(6.20$ minutes). Felipe et al reported no statistically significant difference between groups w.r.t. onset of analgesia. ${ }^{13}$ Usage of equal doses of levobupivacaine and bupivacaine were reported in various studies and procedures to provide similar onset of sensory block (8-30 min), maximum cephalic spread (T7-T8) and duration of analgesia (4-6 h). ${ }^{14,15}$

Author report the onset of motor block (Bromage scale 1) to be quicker in bupivacaine group than in levobupivacaine group. Kopacz DJ et al also reported the onset of motor block to be delayed with levobupivacaine. ${ }^{16}$ In both the studies the difference was insignificant statistically. Present findings corroborate available literature. Further, various studies have reported longer onset and less intense motor block with S75-R25 Bupivacaine as compared to bupivacaine. ${ }^{17,18}$

As for comparison of time to achieve height $\mathrm{T} 6$ for analgesia (to start surgery) in the two groups, in levobupivacaine group surgery could be started significantly early. Felipe et al found statistically insignificant difference in favor of levobupivacaine w.r.t. time to start surgery; while others reported no difference between the two groups. ${ }^{13-15}$

Author report the duration of postoperative analgesia in both bupivacaine and levobupivacaine group to be similar. Casati et al also reported that equipotent dosage of levobupivacaine and bupivacaine provide comparable post-operative pain relief and recovery of sensory and motor function. ${ }^{15}$ The levobupivacaine and bupivacaine, when used in thoracic epidural anesthesia, provide comparable duration of post-operative analgesia after thoracic surgery. ${ }^{19}$ It is also reported in the literature that addition of opioids (fentanyl, morphine) improves the quality and duration of post-operative analgesia. ${ }^{20}$

Recovery from motor block was significantly earlier in levobupivacaine group (Bromage scale 2: 1.5 hours in levobupivacaine group and 2.5 hours in bupivacaine group). This finding also sits well available literature. ${ }^{15,17}$

\section{CONCLUSION}

In conclusion, levobupivacaine fared significantly better on all the parameters, except motor block onset, the difference there being statistically insignificant. So; levobupivacaine is recommended over racemic bupivacaine for epidural block in patients undergoing elective cesarean section.

\section{ACKNOWLEDGEMENTS}

Authors would like to thank Dr. Deshmukh S and Dr. Deshmukh R, Department of Anaesthesia in the form of constant encouragement and whole-hearted support in successful conduction of the study.

Funding: No funding sources

Conflict of interest: None declared

Ethical approval: The study was approved by the Institutional Ethics Committee

\section{REFERENCES}

1. Cox CR, Faccenda KA, Gilhooly C, Bannister J, Scott NB, Morrison LM. Extradural S (-) - bupivacaine: Comparison with racemic RS- bupivacaine. $\mathrm{Br} \mathrm{J}$ Anaesth. 1998;80:289-93.

2. Ryu HY, Kim JY, Lim HK, Yoon J, Yoo BS, Choe $\mathrm{KH}$, et al. Bupivacaine induced cardiac toxicity mimicking an acute non-ST segment elevation myocardial infarction. Yonsei Med J. 2007;48:331-6.

3. Foster RH, Markham A. Levobupivacaine: A review of its pharmacology and use as a local anaesthetic. Drugs. 2000;59:551-79.

4. Leone S, Di Cianni S, Casati A, Fanelli G. Pharmacology, toxicology and clinical use of new long acting local anesthetics, ropivacaine and levobupivacaine. Acta Biomed. 2008;79:92-105.

5. Burlacu CL, Buggy DJ. Update on local anesthetics: Focus on levo- bupivacaine. Ther Clin Risk Manag. 2008;4:381-92.

6. Bromage PR. Epidural Analgesia. WB Saunders, Philadelphia; 1978:144.

7. Breen TW. Epidural anesthesia for labor in an ambulatory patient. Anesth Analg. 1993;77:919-24.

8. Morrison SG, Dominguez JJ, Frascarolo P. A comparison of the eletrocardiographic cardiotoxic effects of racemic bupivacaine, levobupivacaine, and 
levobupivacaine in anesthetized swine. Anesth Analg. 2000;90:1308-14.

9. Fesih K, Hüsnü K. Comparison of the effects of epidural $0.5 \%$ bupivacaine and $0.5 \%$ levobupivacaine administration on anesthesia quality, side effect incidence, and analgesia requirement times in hip and lower extremity surgery. Turk J Med Sci. 2013;43:580-5.

10. Rita C, Gabriele V. Comparative study between Levobupivacaine and Bupivacaine for hernia surgery in the elderly. BMC Surg. 2012;12: S12.

11. Nauman A, Abdul Z, Abdullah AA, Sabah AJ, Waleed R. Comparison of Levobupivacaine $0.5 \%$ or Bupivacaine $0.5 \%$ Both in a Mixture with Lidocaine $2 \%$ for Superficial Extraconal Blockade. Middle East Afr J Ophthalmol. 2012;19(3):330-3.

12. Bader AM, Tsen LC, Camann WR. Clinical effects and maternal and fetal plasma concentrations of $0.5 \%$ epidural levobupivacaine versus bupivacaine for cesarean delivery. Anesthesiol. 1999;90:1596-601.

13. Felipe B, Vanessa RB. Levobupivacaine versus Bupivacaine in Epidural Anesthesia for Cesarean Section. Comparative Study. Rev Bras Anestesiol. 2005;55(6):606-13.

14. Cox CR, Faccenda KA, Gilhooly C, Bannister J, Scott NB, Morrison LM. Extradural S(-)-bupivacaine: Comparison with racemic RS-bupivacaine. $\mathrm{Br} \mathrm{J}$ Anaesth. 1998;80:289-93.

15. Casati A, Santorsola R, Aldegheri G, Ravasi F, Fanelli $\mathrm{G}$, Berti M, et al. Intraoperative epidural anesthesia and postoperative analgesia with levobupivacaine for major orthopedic surgery: A double-blind, randomized comparison of racemic bupivacaine and ropivacaine. J Clin Anesth. 2003;15:126-31.

16. Kopacz DJ, Allen HW, Thompson GE. A comparison of epidural levobupivacaine $0.75 \%$ with racemic bupivacaine for lower abdominal surgery. Anesth Analg. 2000;90:642-8.

17. Butterworth J - Local anesthetics: pharmacology and clinical use. IARS. 2002;22-6.

18. Hollmann MW, Durieux ME, Graf BM. Novel local anesthetics and novel indications for local anesthetics. Curr Opin Anaesthesiol. 2001;14:741-9.

19. Cok OY, Eker HE, Turkoz A, Findikcioglu A, Akin S, Aribogan A, et al. Thoracic epidural anesthesia and analgesia during the perioperative period of thoracic surgery: Levobupivacaine versus bupivacaine. J Cardiothorac Vasc Anesth. 2011;25:449-54.

20. Crews JC, Hord AH, Denson DD, Schatzman C. A comparison of the analgesic efficacy of $0.25 \%$ levobupivacaine combined with $0.005 \%$ morphine, $0.25 \%$ levobupivacaine alone, or $0.005 \%$ morphine alone for the management of postoperative pain in patients undergoing major abdominal surgery. Anesth Analg. 1999;89:1504-9.

Cite this article as: Pahuja HD, Tajne MP, Bhure AR, Chauhan SM. Bupivacaine $0.5 \%$ vs. levobupivacaine $0.5 \%$ for epidural anaesthesia for caesarean section: a comparative study. Int J Basic Clin Pharmacol 2018;7:343-7. 